\title{
Differences In Work-Related Values Between The Mexican-American And Anglo-American Accounting Professionals
}

Glen D. Moyes, (E-mail: glenmoyes@utpa.edu), University of Texas-Pan American Angelica C. Cortes, University of Texas-Pan American

\begin{abstract}
This study examines differences in job satisfaction work-related values between the MexicanAmerican and Anglo-American Accounting Professionals. Survey instruments were sent to accounting alumnae of two universities: (1) a primarily Mexican-American university and (2) a primarily Anglo-American university. Factor analysis and logistic regression were performed. When analyzing between groups, the findings indicated that while Mexican-American respondents are less satisfied with compensation, benefits and supervisors, they have greater overall job satisfaction than the Anglo-American respondents. These results are also statistically significant when the two groups are compared by gender and age. However, within group the results indicated that Anglo-Americans females are more satisfied with benefits and coworkers than their male counterparts; whereas there is no significant difference within the Mexican-American group by gender. One explanation is that the Mexican-Culture includes values such as loyalty to one's employer and appreciation for job longevity, whereas Anglo-American has a greater appreciation for job mobility.
\end{abstract}

\section{INTRODUCTION}

T

his study examines cultural aspects that affect work-related values between Mexican-American and AngloAmerican accounting professionals. Using a survey instrument, the responses between Mexican-American and Anglo-American accounting professionals were compared on several dimensions. Results indicate that while Mexican-American respondents are less satisfied with individual work-related values such as compensation, benefits and supervisors, they have greater overall job satisfaction than Anglo-American respondents. These results are also statistically significant when the two groups are compared by gender and age. One explanation is that Mexican-Americans incorporate values such as loyalty to one's employer and appreciation for longevity on the job found in the Mexican culture.

By examining work-related values of Mexican-American accounting professionals, this paper contributes to the literature on cultural diversity in the workforce. The Hispanics comprise an estimated 35.3 million of the U.S. population and as the Hispanic population is projected to grow to approximately 25 percent of the U.S. population by 2050 (2000 U.S. Census Bureau, 2001), it is increasingly important for the accounting profession to recruit and retain more Hispanic accountants. Approximately 67 percent of Hispanics in the United States are Mexican by origin (Ramirez, 2000). A greater awareness and appreciation of issues confronting Mexican-Americans, as a minority group, should assist employers in improving retention and increasing job satisfaction of the Mexican-American accounting professional.

The remainder of this paper is structured as follows. The second section provides a review of cultural related-work values for this study. The third section describes the research design and database. The fourth section presents discussion of the results and implications of the statistical tests. The fifth section presents the conclusions and the limitations of the study and suggestions for future research. 


\section{CULTURAL WORK-RELATED VALUES}

Hofstede's work-values help to provide the cultural background of these two groups of accounting professionals comprised by Mexican-Americans and Anglo-Americans. It is relevant to use both countries' factors because in general, Mexican-Americans tend to be very strongly identified with Mexico's cultural characteristics. Hofstede (1980, 2001) identified four work-related values: (1) Power Distance, (2) Individualism/Collectivism, (3) Femininity/Masculinity, and (4) Uncertainty Avoidance. According to Hosfede (1980, 2001), the United States and Mexico differ in all four work-values factors.

Power Distance refers to how people within an organization feel about differentials in authority and status associated with organizational ranks. The United States is low in power distance ranking 40 among 50 countries, whereas Mexico ranks in the top 5 of high power distance. Hofstede bases this dimension on Mulder's (1977) definition of power, which is the potential to direct or determine the behavior of another person more so than the other way round. Individualism/Collectivism involves the tendency of the culture to be person-centered or group-centered. The United States is characterized as an individualistic society with a ranking of 1 in individualism, whereas Mexico is characterized as a collectivist society with a ranking of 32 (mid-range between individualism and collectivism). In highly individualist societies, one is responsible only for oneself, whereas collectivist societies tend to emphasize cooperation and work better with work-teams. Triandis (1994) indicates that people with strong individualist values emphasize autonomy, independence and individual initiatives, whereas people with collectivist values emphasize solidarity to their ingroups, obligations, security, duty and personalized relationships.

Femininity/Masculinity concerns traditional values of quality of life versus quantity of life or materialism. Both countries show some similarities in this dimension with the United States ranking $15^{\text {th }}$ in masculinity, whereas Mexico ranks $6^{\text {th }}$ in masculinity. Masculine societies tend to emphasize earnings as more important than interesting work; there is less conformity; confrontations are expected; and managers exhibit more leadership, independence and assertiveness. However, even when Mexico is also considered a masculine society, people tend to avoid confrontations and there is an emphasis on belonging. Uncertainty Avoidance regards the level of certainty in workrules such as job security and seniority. These two countries show a difference in this factor: (1) United States ranks $43^{\text {rd }}$ which indicates low uncertainty avoidance, and (2) Mexico ranks $18^{\text {th }}$ which indicates high uncertainty avoidance.

In Mexico, as a high uncertainty avoidance culture, employees tend to stay with the same employer and feel managers should be selected on the basis of seniority. In low uncertainty avoidance, like the United States, the opposite is true. Employees are less hesitant to change employers and feel managers should be selected on criteria other than seniority, such as education, experience, expertise, etc.

These Mexican cultural work-related value dimensions have been found to carry over in the MexicanAmerican group, even as far as the second generation born in the United States due to their strong family traditions. Weaver (2000) found that Mexican-Americans had experienced less acculturation than other groups. In his study comparing Euro-Americans and Mexican-American work attitudes, Weaver (2000) found that Mexican-Americans were younger and less well-educated compared to their Euro-American counterparts, which also influenced their level of earnings, and with a significant low degree of representation at higher managerial levels. In another study, Gomez (2003) found that acculturation is influenced by academic achievement, occupational status, and income. However, Sabogal et al (1987) found that as Hispanics become more acculturated, the strength of some of their cultural dimensions begin to weaken, e.g., their strong identification with their family. In addition, Gomez (2003) found that education is a key element of acculturation and that highly acculturated Hispanics have higher levels of individualism than Hispanics of lower levels of acculturation. The more acculturated the individuals are, the weaker are the collectivist characteristics which are strongly identified with Hispanic culture, and so the greater is their identification with individualist dimensions.

In contrast, our study examines specific differences in the importance of work-related values between Mexican-American and Anglo-American professional accountants. The Mexican-Americans in this study are alumnae of a Texas university located in proximity to the Mexican border. Most of the alumnae are first or second generation Mexican-Americans with close ties to the Mexican community. Thus, we predict that some of the cultural 
dimensions identified by Hofstede (1980), Triandis (1994) and Gomez (2003) will play a role in distinguishing between these two groups. The authors did not measure the level of acculturation per se. However, the respondents identified themselves as members of one of the two groups. According to Phinney (1996), self-identification into an ethnic group is critical in such research.

\section{RESEARCH DESIGN AND DATABASE}

A survey instrument was designed to examine differences in job satisfaction work-related values between these two groups. Questionnaires were sent to a random sample of accounting graduates from the two universities. The university with an Anglo-American dominated student body is located in the state of New York. The second university with a student body of approximately 95 percent Mexican-Americans is located in Texas in the Mexican border region. The Texas university was ranked as one of the top twenty-five colleges for Mexican-Americans in 1996 (Sosa, 1998).

The questionnaire contains 12 background questions (e.g., ethnicity, gender), 12 questions related to the work environment (e.g., profession, job title), nine questions related to mentoring, and 78 questions using a six-point Likert scale addressing work related-values and job satisfaction. The final unstructured section asks the respondents for additional comments on level of job satisfaction related to their current positions.

The questionnaire was designed with 78 questions addressing work related-values and job satisfaction. The first 36 questions are taken from the Job Satisfaction Survey (Spector, 1985). This survey has been used extensively and shown to have high internal consistency, test-retest reliability over time, and validity (Smith et al., 1969). The remaining 42 questions are based on a survey instrument developed by Moyes and Quigley (Moyes et al., 2000). The questionnaire was designed to examine the relationship between gender, ethnicity and job satisfaction.

The authors conducted a pilot test of the questionnaire in several universities. The participants were asked to complete the questionnaire based on their experiences with current and prior employers. As a result of the pilot test, additional revisions to the instrument were made.

One thousand questionnaires were sent to randomly-selected accounting graduates from each of the two universities. To achieve random selection, every fourth name was selected. Names and addresses were supplied by the alumnae office of the two universities. Responses to the first mailing were 156 and 119 from the New York and Texas universities, respectively. A second mailing resulted in 91 additional responses from the New York university and 87 from the Texas university. The overall response rate from each group was 25 and 21 percent, respectively.

Some surveys were eliminated from the sample for the following reasons. First, incomplete questionnaires were removed. Second, for the university located in New York, respondents who did not identify themselves as Anglo-American in the question regarding ethnicity/nationality were eliminated. Similarly, respondents from the Texas university, who did not select "Mexican-American" or "Mexican" in the ethnicity/nationality category were also excluded. This filtering resulted in samples of 193 and 149 for the New York and Texas universities, respectively.

A test of nonresponse bias was conducted on both samples to determine if sample responses were representative of the total population. For this test, late respondents are used as proxies for nonrespondents (Oppenheim, 2001). Hotellings $\mathrm{T}^{2}$ was used to test the equality of the multivariate means of the first and second mailings. The results of the test indicated no significant difference between early and late respondents.

\section{DISCUSSION OF RESULTS}

\section{Descriptive Statistics}

Table 1 compares the respondents from the two groups on 19 variables. The results of a comparison between the two groups on background and work environment reflect their geographic differences. In general, the MexicanAmerican group is four years older than the Anglo-American group. This difference is significant $(\mathrm{p}>.001)$. On the 
average, the Mexican-Americans in the sample took about 2 years longer to complete their bachelor degrees than the Anglo-American group. Although this issue was not addressed in the questionnaire, several factors could explain this finding: (1) Most of the Mexican-American group are more likely to work full-time while attending school, (2) Students receive less financial assistance (that is, scholarship, financial aid or parental support) requiring them to drop out for a semester to work. These changes may extend their time at the university.

Table 1: T-tests for Equality of Means Between Anglo-American and Mexican-American Respondents on Background Information, Work Environment and Mentoring

\begin{tabular}{|c|c|c|}
\hline & \multicolumn{2}{|c|}{ Mean Response } \\
\hline & Anglo-American & Mexican-American \\
\hline & $\mathrm{N}=193$ & $\mathrm{~N}=149$ \\
\hline \multicolumn{3}{|l|}{ Gender: } \\
\hline Female & $\mathrm{N}=69$ & $\mathrm{~N}=85$ \\
\hline Male & $\mathrm{N}=124$ & $\mathrm{~N}=64$ \\
\hline Year of Birth & 1970 & $1966 * * * * *$ \\
\hline $\begin{array}{l}\text { Year of Graduation } \\
\text { (Bachelor Degree) }\end{array}$ & 1993 & 1992 \\
\hline $\begin{array}{l}\text { Degrees } \\
\quad(\mathrm{BS}=1 ; \mathrm{MBA}=2)\end{array}$ & 1.70 & $1.16^{* * * * * *}$ \\
\hline $\begin{array}{l}\text { Certifications } \\
\quad(\text { None }=0 ; \mathrm{CPA}=1)\end{array}$ & .90 & $.62 *$ \\
\hline \multicolumn{3}{|l|}{ Highest Level of: } \\
\hline Education of Parent & Junior/Community College & High School***** \\
\hline $\begin{array}{l}\text { Internship } \\
\quad(\text { No }=0 ; \text { Yes }=1)\end{array}$ & .33 & $.13 * * * * *$ \\
\hline Years in Current Position & 2.90 years & 4.93 years $* * * * *$ \\
\hline No. of Employees & $500-999$ & $100-499 * * * * *$ \\
\hline$\%$ of Female Employees & $40.6 \%$ & $46.9 \% * * *$ \\
\hline$\%$ Anglo-American Employees & $69.7 \%$ & $40.3 \% * * * * *$ \\
\hline$\%$ Mexican-American Employees & $10.0 \%$ & $63.8 \% * * * * *$ \\
\hline $\begin{array}{l}\text { Supervisor-Same Race/Ethnicity } \\
(\text { No }=0 ; \text { Yes }=1)\end{array}$ & .76 & $.60 * * * *$ \\
\hline $\begin{array}{l}\text { Mentor Assigned } \\
\quad(\text { No }=0 ; \text { Yes }=1)\end{array}$ & .67 & .59 \\
\hline $\begin{array}{l}\text { Mentor-Same Sex } \\
(\text { No }=0 ; \text { Yes }=1)\end{array}$ & .55 & .47 \\
\hline $\begin{array}{l}\text { Mentor-Same Race/Ethnicity } \\
\quad(\text { No }=0 ; \text { Yes }=1)\end{array}$ & .67 & $.44 * * * *$ \\
\hline Mentor-Same Office & .80 & $.68^{*}$ \\
\hline Discussions with Mentor & Rarely to Occasionally & Occasionally to Frequently****** \\
\hline Mentoring Experience & Somewhat Rewarding & Somewhat Rewarding \\
\hline
\end{tabular}

A significantly smaller number of the Mexican-Americans had internships as undergraduates. In comparison, most of the accounting majors in the university located in the state of New York participated in internships during their bachelor program. Firm size is also reflected in the number of total employees reported in companies for which the graduates currently work. On average, the Mexican-American respondents work for firms employing between 100 and 499 employees; whereas, the Anglo-American respondents work for firms employing between 500 and 999 employees. The Anglo-American group includes a statistically significant more MBA's and CPA's compared to the Mexican-American group. This result is not surprising given the more competitive environment of larger firms in metropolitan areas. 
Due to Mexican-Americans' loyalty to family and employer, Sosa (1998) indicates that Hispanics strongly rely on their families for support, and they are reluctant to move away even if means a better job opportunity. It is not surprising that there is a statistically significant difference in the number of years that Mexican-American respondents have remained in their current position. While the average Anglo-American respondent has been with the same firm for slightly under three years, the average Mexican-American has remained with the same employer for almost five years.

For further evidence of Mexican-American unwillingness to relocate, the postmarks on the return envelopes of the respondents were recorded. For the Anglo-American group, response envelopes have postmarks from 21 states with 42 (21.8 percent) stamped New York City. For the Mexican-American group, there were postmarks from only 3 states with 88.6 percent from Texas, and 75.2 percent from the town in which the university is located. Reluctance to relocate was expressed by one of the Mexican-American respondents:

...A new promotion to a regional or corporate level would require my family to move...I need to weigh promotional opportunities against the upset of moving my family and the current level of job satisfaction that I have. So far, my stability has been more important than the promotions.

Mexican-American respondents report working in companies with a higher level of female employees (46.9 percent versus 40.6 percent for Anglo-American respondents). In 2001, women represented 42 percent of the professional staff employed by all CPA firms (AICPA, 2002). Additionally, the Mexican-American respondents tend to work in firms with a high percentage of Mexican-American employees (63.8 percent). Kanter (1977) defines ratios of 60:40 (that is, six Mexican-Americans to every four Anglo-American) as balanced. She found tokenism and subgroup cultures are less likely to appear in balanced firms leading to a higher employee comfort level and, ultimately, greater job satisfaction. Moyes et al (2000) found consistent findings with African American accounting professionals, who were more comfortable in their work environment with a higher percentage of African American employees.

Discussions with representatives from the Human Resource area of several of the largest international accounting firms (Moyes et al., 2000), indicated the use of mentoring as one of the methods of dealing with diversity in the work environment. In most firms, an effort is made to link a new professional hire to a mentor based on gender and ethnicity. In some instances, the firm can only accomplish this objective by matching the new hire with a mentor in another office or even in another city. This practice is necessary if there is an insufficient number of existing employees that are the same race, ethnicity, and gender as the new hire. Mexican-American respondents in this study indicate that their mentors tend to be of a different ethnicity and located in the same office compared to AngloAmerican respondents. In addition, Mexican-Americans had more interaction with their mentors and viewed the overall experience as more rewarding.

\section{Factor Analysis}

Factor analysis known as principal components was used as a variable reducing scheme to decrease the responses from 78 questions on the questionnaire down to 18 factors, of which 10 factors were retained as determined by scree test (Cattell, 1966) and the remaining eight factors were eliminated for statistical testing. For the questions stated negatively on the questionnaire, the coding of the responses was reversed. To assist in the interpretation of the resulting factors, a varimax rotation (Kaiser, 1960) was applied in the factor analysis. The rotation was necessary to interpret the factors and to eliminate multicolliniarity of the independent variables (Stevens, 1986). Using the criterion of Kaiser (1960), only those components with eigenvalues greater than one were included in the testing. Table 2 presents the ten factors resulting from the factor analysis (principal components) with varimax rotation that were selected as the independent variables for the seven regression models. 
Table 2: Factor Analysis With Varimax Rotation

\begin{tabular}{|l|l|c|c|c|}
\hline \multicolumn{1}{|c|}{ Variable (Name) } & \multicolumn{1}{|c|}{ Sample Statement } & Eigen- value & $\begin{array}{c}\text { Percent of } \\
\text { variance }\end{array}$ & $\begin{array}{c}\text { Cumulative } \\
\text { Percentage }\end{array}$ \\
\hline $\begin{array}{l}\text { 1. JOBSAT } \\
\text { (Job Satisfaction) }\end{array}$ & Overall, I have a high level of job satisfaction & 8.639 & 11.145 & 11.145 \\
\hline $\begin{array}{l}\text { 2. SUPER } \\
\text { (Supervisor) }\end{array}$ & I like my supervisor & 6.747 & 8.651 & 19.796 \\
\hline $\begin{array}{l}\text { 3. COMP } \\
\text { (Compensation) }\end{array}$ & I feel I'm paid a fair amount for the work I do & 4.157 & 5.329 & 25.125 \\
\hline $\begin{array}{l}\text { 4. DISCRIM } \\
\text { (Discrimination) }\end{array}$ & $\begin{array}{l}\text { My supervisor does not treat me differently due to } \\
\text { my race/ethnicity }\end{array}$ & 4.151 & 5.322 & 30.447 \\
\hline $\begin{array}{l}\text { 5. COMMUN } \\
\text { (Communication) }\end{array}$ & Organization goals are clearly communicated & 3.877 & 4.970 & 35.418 \\
\hline $\begin{array}{l}\text { 6. BENEFITS } \\
\text { (Benefits) }\end{array}$ & The benefits package we have is equitable & 3.121 & 4.001 & 39.419 \\
\hline $\begin{array}{l}\text { 7. COMPLAINT } \\
\text { (Complaint) }\end{array}$ & $\begin{array}{l}\text { I would not be afraid to report a discriminatory act } \\
\text { against me to my supervisor }\end{array}$ & 3.080 & 3.949 & 43.368 \\
\hline $\begin{array}{l}\text { 8. COWORK } \\
\text { (Coworkers) }\end{array}$ & I like the people I work with & 2.562 & 3.284 & 46.653 \\
\hline $\begin{array}{l}\text { 9. DIVERSE } \\
\text { (Diversity) }\end{array}$ & $\begin{array}{l}\text { My organization provides meetings and workshops } \\
\text { on cultural diversity }\end{array}$ & 2.507 & 3.214 & 49.866 \\
\hline $\begin{array}{l}\text { 10. APPREC } \\
\text { (Appreciation) }\end{array}$ & I feel the work I do is appreciated & 2.461 & 3.155 & 53.022 \\
\hline
\end{tabular}

For the largest of the ten factors retained, JOBSAT, 13 of the 78 questions comprised this component. The questions included in this factor are level of job satisfaction, pride in doing one's job (e.g. "I feel sense of pride in doing my job"), intention of remaining with employer (e.g. "I intent to remain with my current employer"), and enjoying work tasks. The second factor, SUPER, includes 12 questions regarding the employee's supervisor. These questions address the employee's general attitude toward the supervisor (e.g., "I like my supervisor"), and the role of the supervisor in helping the employee reach his or her work-related goals (e.g., "My supervisor assigns me projects that increase my visibility in the organization").

The third factor selected, COMP, involves compensation and has seven questions which included level of pay, raises, and the fairness of the compensation for the work required (e.g. "I am paid fair amount for work I do" and "I am satisfied with my chances for salary increases"). Eight questions associated with gender and ethnic discrimination loaded on the fourth factor, DISCRIM, (e.g., "My peers treat me differently because of my gender" and "My supervisor treats me differently than peers due to my race [ethnicity"). The fifth factor, EVIRON, centers on the organizational environment consisting of six questions (e.g., "Organizational goals are clear," "There is not too much bickering and fighting at work" and "My work assignments are fully explained").

The benefits the employee receives and an assessment of how these benefits compare with the package provided by other companies are four questions included in the sixth factor, BENEFITS, (e.g. I am satisfied with benefits I receive" and "Benefit package we have is equitable"). The four questions making up the seventh factor, COMPLAINT, involves the company's handling of discrimination complaints, (e.g., "I would not be afraid to report of sexual harassment" and "I am not afraid to report a discriminatory act against me").

The eighth factor, COWORKER, addresses the employee's opinion of co-workers with only two questions (e.g., "I like my coworkers" and "I enjoy my coworkers"). Factor nine, DIVERSE, includes three questions related to diversity programs initiated by the employer, (e.g. "Organization provides meetings on cultural diversity," and "My company encourages openness on gender/racial diversity"). The tenth and final factor, APPREC, includes four questions related to how appreciated the employee feels in the organization (e.g., "I feel the work I do is appreciated," and "My opinions are respected same as those of others"). 


\section{Regression Models: Differences Between Groups by Gender and Age}

The differences in job satisfaction work-related values between the Mexican-American and Anglo-American accounting professionals are presented in Table 3 which contains five models with the ten independent variables explained in Table 2. Model 1 is between groups --all Mexican-American respondents and all Anglo-American respondents. Models 2 and 3 are between groups compared by gender. Models 3 and 4 are between groups compared by age. In further testing, Model 6 and 7 analyzed within groups differences by gender.

Model 1 tests ethnic differences between Mexican-American and Anglo-Americans accounting professionals concerning job satisfaction work-related values. Logistic regression was used since the dependent variable, ETHNICITY, is dichotomous (e.g., Mexican-American/Anglo-American). Model 1 (Table 3, panel A) is presented below:

Model 1: ETHNICITY (Mexican-American /Anglo-American) $=b_{0}+b_{1}$ JOBSAT $+b_{2}$ SUPER + $b_{3} \mathrm{COMP}+b_{4} \mathrm{DISCRIM}+b_{5}$ EVIRON $+b_{6}$ BENEFITS $+b_{7}$ COMPLAINT $+b_{8}$ COWORK $+b_{9}$ DIVERSE $+b_{10} \mathrm{APPREC}+\epsilon$

Table 3: Logistic Regressions - Between Groups

Panel A: Differences between Mexican-American and Anglo-American accounting professionals concerning job satisfaction work-related values

Model 1: $\quad$ ETHNICITY (Mexican-American/Anglo-American) $=b_{0}+b_{1} \mathrm{JOBSAT}+b_{2} \mathrm{SUPER}+b_{3} \mathrm{COMP}+b_{4} \mathrm{DISCRIM}+b_{5}$ EVIRON $+b_{6}$ BENEFITS $+b_{7}$ COMPLAINT $+b_{8}$ COWORK $+b_{9}$ DIVERSE $+b_{10}$ APPREC $+\epsilon$

\begin{tabular}{|c|c|c|c|c|c|c|c|c|c|c|c|}
\hline Coefficient & $b_{0}$ & $b_{1}$ & $b_{2}$ & $b_{3}$ & $b_{4}$ & $b_{5}$ & $b_{6}$ & $b_{7}$ & $b_{8}$ & $b_{9}$ & $b_{10}$ \\
\hline Parameter & -.325 & $.653 * * * * *$ & $-.366 * *$ & $-.387 * *$ & -.068 & $.353 * *$ & $-.359 * *$ & $-.400 * *$ & -.021 & -.165 & -.077 \\
\hline Model: & & & & & & & & & & & \\
\hline Chi-Square & & $43.481 * * * * *$ & & & & & & & & & \\
\hline
\end{tabular}

where: $\quad$ ETHNICITY $=$ a dichotomous variable with $1=$ Mexican-American, and $0=$ Anglo-American JOBSAT, SUPER, COMP, DISCRIM, EVIRON, BENEFITS, COMPLAINT, COWORK, DIVERSE and APPREC are explained on pages $11 \& 12$.

Panel B : Differences between Mexican-American males and Anglo-American males accounting professionals concerning job satisfaction work-related values

Model 2: ETHNICITY-MALE (Mexican-American Male /Anglo-American Male) $=b_{0}+b_{1} \mathrm{JOBSAT}+b_{2} \mathrm{SUPER}+b_{3} \mathrm{COMP}+$ $b_{4} \mathrm{DISCRIM}+b_{5}$ EVIRON $+b_{6} \mathrm{BENEFITS}+b_{7} \mathrm{COMPLAINT}+b_{8} \mathrm{COWORK}+b_{9}$ DIVERSE $+b_{10} \mathrm{APPREC}+\epsilon$

\begin{tabular}{|l|c|c|c|c|c|c|c|c|c|c|c|}
\hline Coefficient & $b_{0}$ & $b_{1}$ & $b_{2}$ & $b_{3}$ & $b_{4}$ & $b_{5}$ & $b_{6}$ & $b_{7}$ & $b_{8}$ & $b_{9}$ & $b_{10}$ \\
\hline Parameter & $-.679 * * * *$ & $.653^{* *}$ & -.435 & $-.441^{*}$ & -.197 & .325 & -.271 & $-.755^{* * *}$ & .127 & -.023 & -.038 \\
\hline Model: & & & & & & & & & & \\
\hline C.hi-Square & & & & & & & & & & \\
\hline
\end{tabular}

where: ETHNICITY-MALE $=$ a dichotomous variable with $1=$ Mexican-American Male, and $0=$ Anglo-American Male JOBSAT, SUPER, COMP, DISCRIM, EVIRON, BENEFITS, COMPLAINT, COWORK, DIVERSE and APPREC are explained on pages $14 \& 15$. 
Panel C: Differences between Mexican-American females and Anglo-American females accounting professionals concerning job satisfaction work-related values

Model 3: ETHNICITY-FEMALE (Mexican-American Female/Anglo-American Female) $=b_{0}+b_{1} \mathrm{JOBSAT}+b_{2} \mathrm{SUPER}+$ $b_{3} \mathrm{COMP}+b_{4} \mathrm{DISCRIM}+b_{5} \mathrm{EVIRON}+b_{6} \mathrm{BENEFITS}+b_{7} \mathrm{COMPLAINT}+b_{8} \mathrm{COWORK}+b_{9} \mathrm{DIVERSE}+b_{10} \mathrm{APPREC}+\epsilon$

\begin{tabular}{|l|c|c|c|c|c|c|c|c|c|c|c|}
\hline Coefficient & $b_{0}$ & $b_{1}$ & $b_{2}$ & $b_{3}$ & $b_{4}$ & $b_{5}$ & $b_{6}$ & $b_{7}$ & $b_{8}$ & $b_{9}$ & $b_{10}$ \\
\hline Parameter & .120 & $.771 * * *$ & -.307 & -.317 & .178 & .262 & $-.479 * *$ & -.125 & -.189 & -.214 & -.017 \\
\hline Model: & & & & & & & & & & & \\
\hline Chi-Square & & $21.545 * *$ & & & & & & & & & \\
\hline
\end{tabular}

where: ETHNICITY-FEMALE $=$ a dichotomous variable with $1=$ Mexican-American Female, and $0=$ Anglo-American Female

JOBSAT, SUPER, COMP, DISCRIM, EVIRON, BENEFITS, COMPLAINT, COWORK, DIVERSE and APPREC are explained on pages $11 \& 12$.

Panel D: Differences between younger Mexican-American and younger Anglo-American accounting professionals concerning job satisfaction work-related values

Model 4: ETHNICITY-YOUNGER (Younger Mexican-American/Younger Anglo-American) $=b_{0}+b_{1} \mathrm{JOBSAT}+b_{2} \mathrm{SUPER}+$ $b_{3} \mathrm{COMP}+b_{4} \mathrm{DISCRIM}+b_{5}$ EVIRON $+b_{6} \mathrm{BENEFITS}+b_{7} \mathrm{COMPLAINT}+b_{8} \mathrm{COWORK}+b_{9} \mathrm{DIVERSE}+b_{10} \mathrm{APPREC}+\epsilon$

\begin{tabular}{|c|c|c|c|c|c|c|c|c|c|c|}
\hline Coefficient & $\begin{array}{c}B_{1} \\
586 *\end{array}$ & $b_{2}$ & $b_{3}$ & $b_{4}$ & $b_{5}$ & $b_{6}$ & $b_{7}$ & $b_{8}$ & $b_{9}$ & $b_{10}$ \\
\hline $\begin{array}{l}\text { Parameter } \\
\text { Model: }\end{array}$ & $.586^{* *}$ & $-.194 * *$ & -.259 & -.097 & .277 & $-.418 *$ & -.289 & -.054 & -.118 & -.314 \\
\hline $\begin{array}{l}\text { Chi-Square } \\
\text { Number of Observations: }\end{array}$ & $\begin{array}{l}20.138 * * \\
182\end{array}$ & & & & & & & & & \\
\hline
\end{tabular}

where: ETHNICITY-YOUNGER $=$ a dichotomous variable with $1=$ Young Mexican-American, and $0=$ Young AngloAmerican JOBSAT, SUPER, COMP, DISCRIM, EVIRON, BENEFITS, COMPLAINT, COWORK, DIVERSE and APPREC are explained on pages $11 \& 12$.

Panel E: Differences between older Mexican-American and older Anglo-American accounting professionals concerning job satisfaction work-related values

Model 5: ETHNICITY-OLDER (Older Mexican-American/Older Anglo-American) $=b_{0}+b_{1} \mathrm{JOBSAT}+b_{2} \mathrm{SUPER}+b_{3} \mathrm{COMP}+$ $b_{4}$ DISCRIM $+b_{5}$ EVIRON $+b_{6}$ BENEFITS $+b_{7}$ COMPLAINT $+b_{8}$ COWORK $+b_{9}$ DIVERSE $+b_{10}$ APPREC $+\epsilon$

\begin{tabular}{|l|c|c|c|c|c|c|c|c|c|c|c|}
\hline Coefficient & $b_{0}$ & $b_{1}$ & $b_{2}$ & $b_{3}$ & $b_{4}$ & $b_{5}$ & $b_{6}$ & $b_{7}$ & $b_{8}$ & $b_{9}$ & $b_{10}$ \\
\hline Parameter & .139 & $.668 * *$ & $-.752 * *$ & $-.835 * * *$ & -.121 & $.578^{* *}$ & $-.620^{* *}$ & $-.829 * * *$ & .065 & -.378 & -.090 \\
\hline Model: & & & & & & & & & & \\
\hline Chi-Square & & & & & & & & & & & \\
\hline
\end{tabular}

where: ETHNICITY-OLDER $=$ a dichotomous variable with $1=$ Older Mexican-American, and $0=$ Older Anglo-American JOBSAT, SUPER, COMP, DISCRIM, EVIRON, BENEFITS, COMPLAINT, COWORK, DIVERSE and APPREC are explained on pages $11 \& 12$.

$*, * *, * * *, * * * *, * * * * *$ Significant at $.10, .05, .01, .005, .001$, respectively

In addition to the primary relation, subgroups of the sample were tested. Reponses to work-related studies frequently differed according to the respondent's gender (Spector 1997) and age (Williams et al. 2004). To examine this relation, four additional tests were performed subdividing the sample by gender and age. The results for these regressions appear in Table 3, panels B through E. 
The first logistic regression (Table 3, panel A), examines the relation between the ten job satisfaction-related variables for the full sample. The dependent variable, ETHNICITY, is coded 1 if the respondent is MexicanAmerican and 0 if Anglo-American. Thus, a positive coefficient indicates a higher importance of the job satisfaction work-related variable to Mexican-Americans. Conversely, a negative sign indicates a greater significance of the variable to Anglo-Americans. The results of the test show that Anglo-Americans regard supervisors, compensation, benefits and the freedom to file complaints regarding ethnic and gender discrimination more positively than MexicanAmericans $(\mathrm{p}>.05)$. On the other hand, Mexican-Americans respond more favorably to the work environment ( $p$.05). This is consistent with Gomez (2003) findings.

The ENVIRON factor includes communication within the organization, sensitivity to employees' feelings, harmony among employees, and the clarity of organizational goals. This factor, indicating the greatest statistically significant difference between the two groups, involves different levels of job satisfaction $(p>.001)$. In spite of considering pay, benefits, and supervisor less positively than Anglo-Americans, the results of the test indicated significantly greater job satisfaction among Mexican-Americans. Some of the items included in this factor are enjoyment of work and work tasks, satisfaction with choice of employer, intention to remain with current employer, and a high level of job satisfaction. These are all contextual job attributes that are important for individuals showing lower levels of acculturation and higher degree of collectivism as indicated by Gomez (2003), Marin and Triandis (1985), and Weaver (2000).

The finding that Mexican-Americans indicated a higher degree of job satisfaction is unexpected because they were less positive on variables such as pay, benefits and supervisor, which are task-related job attributes. However, the findings are consistent with collectivist culture, as indicated by Gomez (2003).

Although the negative sign on the DISCRIM variable indicates that Anglo-Americans perceive less discrimination than Mexican-Americans, the coefficient is not significant. This result is expected since the average Mexican-American respondent is employed in a firm, where approximately 64 percent of the employees are of a similar ethnic affiliation. Thus, discrimination should not be a major issue. Nonetheless, one respondent wrote the following in the comment section of the questionnaire:

I believe racial discrimination is alive in America, because I see it at my place of work. Anglos dominate the higher paying jobs and Mexican-Americans are kept at lower paying positions, relating to what I call the "MexicanAmerican" glass ceiling.

There is evidence that the attitude toward job satisfaction work-related values change based on gender, (Williams et al., 2004) which is examined in Model 2. Using the same model as in the above, the sample was divided along these variables.

Model 2 analyzed between groups differences by gender. The dependent variable, ETHNICITY-MALE, in the regression is dichotomous (e.g., Mexican-American males/Anglo-American males). Model 2 (Table 3, panel B) is presented below.

Model 2: ETHNICITY-MALE (Mexican-American male /Anglo-American male) $=b_{0}+$ $b_{1} \mathrm{JOBSAT}+b_{2} \mathrm{SUPER}+b_{3} \mathrm{COMP}+b_{4} \mathrm{DISCRIM}+b_{5}$ EVIRON $+b_{6}$ BENEFITS $+b_{7}$ COMPLAINT + $b_{8} \mathrm{COWORK}+b_{9}$ DIVERSE $+b_{10}$ APPREC $+\epsilon$

Although Anglo-American males are more satisfied with pay, the Mexican-American males indicate a statistically significant higher level of job satisfaction. The fact that Anglo-American males are more comfortable than Mexican-Americans in reporting discriminatory actions to supervisors is not surprising, since such actions would rarely occur with this group.

Model 3 tests the job satisfaction work-related values between the Mexican-American and Anglo-American female respondents. The dependent variable, ETHNICITY-FEMALE, in the regression is dichotomous (e.g., AngloAmerican females/Mexican-American females). Model 3 (Table 3, panel C) is presented below. 
Model 3: ETHNICITY-FEMALE (Mexican-American female /Anglo-American female) $=b_{0}+$ $b_{1} \mathrm{JOBSAT}+b_{2} \mathrm{SUPER}+b_{3} \mathrm{COMP}+b_{4}$ DISCRIM $+b_{5}$ EVIRON $+b_{6}$ BENEFITS $+b_{7}$ COMPLAINT + $b_{8} \mathrm{COWORK}+b_{9}$ DIVERSE $+b_{10}$ APPREC $+\epsilon$

As with the male group, job satisfaction is higher for the Mexican-American females than the AngloAmerican female professionals (Table 3, panel C). Nonetheless, the Mexican-American group is less satisfied with benefits (e.g., health insurance) than its Anglo-American counterparts.

There is evidence that the attitude toward job satisfaction work-related values change based on age (Williams et al., 2004). This was examined in Models 4 and 5. Using a variation of the basic model (Model 1), the two groups are compared on the basis of age. The dependent variable, ETHNICITY-YOUNGER, in the regression is dichotomous (e.g., younger Anglo-American/younger Mexican-American). The authors define younger as 32 years of age or lower in 2002, which is the year of the survey. The age of 32 years was selected for two reasons: (1) it was the average age of all respondents, and (2) at this age, most participants in this study should be achieving senior manager or partner consideration Model 4 (Table 3, panel D) is presented below.

Model 4: ETHINICY-YOUNGER (younger Mexican-American/younger Anglo-American $=b_{0}$ $+b_{1}$ JOBSAT $+b_{2}$ SUPER $+b_{3}$ COMP $+b_{4}$ DISCRIM $+b_{5}$ EVIRON $+b_{6}$ BENEFITS $+b_{7}$ COMPLAINT + $b_{8} \mathrm{COWORK}+b_{9}$ DIVERSE $+b_{10}$ APPREC $+\epsilon$

In a comparison of young (age 32 and lower) accounting professionals (Table 3, panel D), MexicanAmericans exhibit greater overall job satisfaction, while Anglo-Americans are more positive about benefits received.

Model 5 compares between older Mexican-Americans and older Anglo-Americans, where Older is defined as being 33 years and over. The dependent variable, ETHNICITY-OLDER, in the regression is dichotomous (e.g., older Anglo-American/older Mexican-American). Model 5 (Table 3, panel E) is presented below.

Model 5: ETHNICITY-OLDER (older Mexican-American/older Anglo-American) $=b_{0}+$ $b_{1} \mathrm{JOBSAT}+b_{2} \mathrm{SUPER}+b_{3} \mathrm{COMP}+b_{4} \mathrm{DISCRIM}+b_{5}$ EVIRON $+b_{6}$ BENEFITS $+b_{7}$ COMPLAINT + $b_{8} \mathrm{COWORK}+b_{9} \mathrm{DIVERSE}+b_{10} \mathrm{APPREC}+\epsilon$

There are greater differences regarding job satisfaction work-related values (Table 3, panel E) between the two older accounting professional groups. While older Mexican-Americans continue to indicate greater job satisfaction, older Anglo-Americans are more positive about supervisors, compensation, benefits, and opportunity to bring discriminatory complaints to management. This is surprising because Anglo-Americans are emphasizing contextual-job attributes, which are characteristic of a collectivist culture.

The results of this study indicate that regardless of group membership (i.e., gender, age) the level of job satisfaction is greater among the Mexican-American respondents than for their Anglo-American counterparts. However, the Mexican-American respondents are less satisfied with specific work-related values, such as pay and benefits, which are contextual job attributes. This sentiment was reiterated in the commentary section of the survey such as:

"I should have studied something else. I am forced to live in the border region because of family situation. The pay here is terrible. Because there are too many accounting majors graduating from this university, and they stay here to compete with each other!"

There were numerous comments by Mexican-Americans regarding their positive level of job satisfaction. Some of these comments are noted below:

"I feel that I am very satisfied in my current position." "The company I work for provides great opportunities for advancement regardless of race or gender." "Job satisfaction is a key to success." "I have a great job and feel I 
was well prepared for it for the most part through my college education. I am in the process of negotiating a buy-out of the CPA firm I work for."

This apparent contradiction between greater dissatisfaction on specific work-related variables yet higher overall satisfaction of the Mexican-American accounting professional, including the desire to remain with one's current employer, can be explained by Hofstede's dimensions. These cultural dimensions include Mexican medium level of masculinity, high level of collectivism, and high level of uncertainty avoidance. These cultural work-values seem to be carried on to the Mexican-American group studied in this research.

\section{Additional Regression Models: Gender Differences Within Groups}

This section presents two further tests that were conducted to analyze the role of gender within each ethnic group. The gender differences in job satisfaction work-related values were examined both within the MexicanAmerican group and within the Anglo-American group of accounting professionals. The authors predict to find significant differences between the males and females within each of these two groups about their level of job satisfaction work-related values. Using the similar models as described above, two logistic regressions (Models 6 and 7) were performed.

Model 6 compares female and male Anglo-Americans pertaining to job satisfaction work-related values. The dependent variable, GENDER-ANGLO-AMERICAN, in the regression is dichotomous (e.g., Anglo-American female/Anglo-American male). Model 6 (Table 4, panel A) is presented below.

Table 4: Logistic Regressions - Within Groups

Panel A : Differences between males and females Anglo-American accounting professionals concerning job satisfaction work-related values

Model 6: GENDER-ANGLO-AMERICAN (Anglo-American Male/Anglo-American Female) $=b_{0}+b_{1} \mathrm{JOBSAT}+b_{2} \mathrm{SUPER}+$ $b_{3} \mathrm{COMP}+b_{4} \mathrm{DISCRIM}+b_{5}$ EVIRON $+b_{6} \mathrm{BENEFITS}+b_{7} \mathrm{COMPLAINT}+b_{8} \mathrm{COWORK}+b_{9} \mathrm{DIVERSE}+b_{10} \mathrm{APPREC}+\epsilon$

\begin{tabular}{|l|l|l|l|l|l|l|l|l|l|l|l|}
\hline Coefficient & $b_{0}$ & $B_{1}$ & $b_{2}$ & $b_{3}$ & $b_{4}$ & $b_{5}$ & $b_{6}$ & $b_{7}$ & $b_{8}$ & $b_{9}$ & $b_{10}$ \\
\hline Parameter & $-.582 * * *$ & -.125 & $-.727 * * *$ & .114 & -.113 & -.015 & $-.432 *$ & $-.611 * *$ & $.439 * *$ & -.013 & .170 \\
\hline Model: & & & & & & & & & & \\
\hline Chi-Square & & $18.613 * * *$ & & & & & & & & \\
\hline
\end{tabular}

where: GENDER-ANGLO-AMERICAN $=$ a dichotomous variable with $1=$ Anglo-American Female, and $0=$ Anglo-American Male

JOBSAT, SUPER, COMP, DISCRIM, EVIRON, BENEFITS, COMPLAINT, COWORK, DIVERSE and APPREC are explained on pages $11 \& 12$.

Panel B: Differences between males and females Mexican-American accounting professionals concerning job satisfaction work-related values

Model 7: GENDER-MEXICAN-AMERICAN (Mexican-American Male/Mexican-American Female) $=b_{0}+b_{1} \mathrm{JOBSAT}+$ $b_{2}$ SUPER $+b_{3}$ COMP $+b_{4}$ DISCRIM $+b_{5}$ EVIRON $+b_{6}$ BENEFITS $+b_{7}$ COMPLAINT $+b_{8}$ COWORK + $b_{9}$ DIVERSE $+b_{10}$ APPREC $+\epsilon$

\begin{tabular}{|l|c|c|c|c|c|c|c|c|c|c|c|}
\hline Coefficient & $b_{0}$ & $b_{1}$ & $b_{2}$ & $b_{3}$ & $b_{4}$ & $b_{5}$ & $b_{6}$ & $b_{7}$ & $b_{8}$ & $b_{9}$ & $b_{10}$ \\
\hline Parameter & .196 & .121 & $-.494 * *$ & .175 & .091 & .165 & -.005 & .112 & .162 & $-.556^{* * *}$ & -.179 \\
\hline Model: & & & & & & & & & & & \\
\hline Chi-Square & & & & & & & & & & \\
\hline
\end{tabular}


where: GENDER-MEXICAN-AMERICAN = a dichotomous variable with $1=$ Mexican-American Female, and $0=$ MexicanAmerican Male JOBSAT, SUPER, COMP, DISCRIM, EVIRON, BENEFITS, COMPLAINT, COWORK, DIVERSE and APPREC are explained on pages $11 \& 12$.

$*, * *, * * *, * * * *, * * * * *$ Significant at $.10, .05, .01, .005, .001$, respectively

Model 6: GENDER-ANGLO-AMERICAN (Anglo-American Male/Anglo-American Female) $b_{0}+b_{1}$ JOBSAT $+b_{2}$ SUPER $+b_{3}$ COMP $+b_{4}$ DISCRIM $+b_{5}$ EVIRON $+b_{6}$ BENEFITS $+b_{7}$ COMPLAINT + $b_{8} \mathrm{COWORK}+b_{9}$ DIVERSE $+b_{10}$ APPREC $+\epsilon$

For the Anglo-American group, the overall model is significant $(\mathrm{P}>.01)$ (Table 4, panel A). Since males are coded 0 , and females 1 , a negative sign indicates greater importance for the male. Conversely, a positive coefficient suggests the variable is of greater significance to the Anglo-American female. Anglo-American females are more satisfied with benefits and coworkers, while Anglo-American males enjoy better relations with supervisors and feel more positive about management's reaction to complaints involving discrimination. It is not surprising that AngloAmerican males view the COMPLAINT factor more positively since, for the most part, they would have little cause to confront management regarding gender or racial discrimination. Their assessment of this factor is most likely based on hearsay, whereas their female counterparts would have more direct knowledge of management's reaction. The lack of significance on the discrimination variable suggests that firms may be more successful in efforts to manage gender diversity.

Model 7 compares job satisfaction work-related values between of female Mexican-American and male Mexican-Americans. The dependent variable, GENDER-MEXICAN-AMERICAN, in the regression is dichotomous (e.g., Mexican-American female/Mexican-American male). Model 7 (Table 4, panel B) is presented below

Model 7: GENDER-MEXICAN-AMERICAN (Anglo-American Male/Anglo-American Female $)=b_{0}+b_{1}$ JOBSAT $+b_{2}$ SUPER $+b_{3}$ COMP $+b_{4}$ DISCRIM $+b_{5}$ EVIRON $+b_{6}$ BENEFITS + $b_{7}$ COMPLAINT $+b_{8}$ COWORK $+b_{9}$ DIVERSE $+b_{10}$ APPREC $+\epsilon$

The Model 7 (Table 4, panel B) is not significant which suggests little difference in job satisfaction workrelated values between the Mexican-American females and Mexican-American males. There are several possibilities why there are no significant differences for the Mexican-American group. The results show consistency with Hofstede's work-values for the country of Mexico, such as high collectivism, high uncertainty avoidance, and medium level masculinity as has been discussed previously. Furthermore, Latin Americans women, as a whole, have significant influence in the Hispanic culture (Sosa, 1998), which also applies to Mexican-American women. In addition, Sosa (1998) found that women are integrated into a society that promotes gender equality.

\section{CONCLUSIONS}

The primary objective of this study is to examine the effect of cultural work-related values upon both Mexican-American and Anglo-American professional accountants. These findings may assist firms in designing and implementing diversity management and mentoring programs. Evidence indicated that Mexican-American accounting professionals retain much from their Mexican cultural work-related values, such as reluctance to relocate, importance of family versus career advancement, employer loyalty, and job longevity. Although less pleased with certain work related-values (e.g., pay and benefits) than their Anglo-American counterparts, the Mexican-Americans in our study indicated greater overall job satisfaction regardless of gender or age. These findings may be influenced by the fact that the Mexican-American group lives and works very close to the border with Mexico allowing them to retain most the cultural values of their country-of-origin. It is this proximity that may explains why they experience a lower degree of acculturation that will indicate a shift toward more individualistic and task-related job attributes, as found by Gomez (2003).

An unexpected finding of this study is that older Anglo-Americans showed greater satisfaction with contextual-job attributes which are characteristics of a collectivist culture, such as satisfaction with supervisors, 
compensation, benefits, and opportunity to bring discriminatory complaints to management. This may be explained as age rather than culture, because these factors are more salient as individuals move closer to retirement age, so these issues become more universal concerns.

These findings indicate that will be helpful to consider the degree of acculturation of the target ethnic group when management decides to implement diversity awareness and mentoring programs. In the context of this study, the Mexican-American group shows a low degree of acculturation due to their proximity to Mexico. This situation may be different when ethnic groups are located in different regions of the United States away from their country-oforigin.

There are two limitations to our study. First, since the Mexican-American sample in the study resides near the Mexican border, the results may not be generalized to the Mexican-American population living in other regions of the United States. For example, perceived discrimination was not significant since the minority group in our study worked in firms with a high percentage of Mexican-Americans (approximately 64 percent). The results would most likely have been different for Mexican-Americans working in firms with a more typical percentage of minority representation. Second, as with any survey instrument, participant responses may be influenced by a social desirability factor that could compromise the results.

The findings of our study suggest areas of further inquiry. First, additional studies of Mexican-American and other Hispanic accounting professionals in different areas of the country could be made to examine the generalizability of our results. Second, further tests of Mexican-Americans in other professions, such as law, engineering, etc., would indicate if they perceive similar importance to the different work-related values and attributes across professions. Finally, work-related values from several cultures can be evaluated to find how they can be integrated into the corporate governance to enhance the effectiveness of the organization operations. To keep pace with the rapidly changing composition of the U.S. workforce, it is critical that companies not only acknowledge but value diversity to maximize the potential of their employees.

\section{REFERENCES}

1. $\quad$ AICPA. (2002). The Supply of Accounting Graduates and the Demand for Public Accounting Recruits- 2002. AICPA. New York, NY.

2. Catell, R. B. (1966). The Scree Test for the Number of Factors. Multivariate Behavioral Research. 1: 245276.

3. Gomez, C. (2003). The Relationship Between Acculturation, Individualism/Collectivism, and Job Attribute Preferences for Hispanic MBAs. Journal of Management Studies. 40(5):1089-1105.

4. Hofstede, G. (1980). Culture's Consequences. International Differences in Work-Related Values. Sage Publications. Thousand Oaks, CA.

5. Hofstede, G. (2001). Culture's Consequences. Comparing Values, Behaviors, Institutions, and Organizations Across Nations. $2^{\text {nd }}$ Ed., Sage Publications: Thousand Oaks, CA.

6. Kaiser, H.F. (1960). The Application of Electronic Computers to Factor Analysis. Educational and Psychological Measurement. 20:141-151.

7. $\quad$ Kanter, R.M. (1977). Men and Women of the Corporation. Basic Books Inc. New York, NY.

8. Marin, G. and H. Triandis. (1985). Allocentrism as an Important Characteristic of the Behavior of Latin Americans and Hispanics. In Diaz Gerrero, R. (Ed.). Cross-Cultural and National Studies in Social Psychology. Elsevier Science Publishers. North-Holland BV: 85-104

9. Moyes, G. D., Williams, P. A., and B. Z. Quigley. (2000). The Relation Between Perceived Treatment Discrimination and Job Fulfillment Among African-American Accounting Professionals. Accounting Horizons. 14(1): 21-48.

10. Mulder, M. (1977). The Daily Power Game. Leyden, Netherlands. Martinus Nijhoff.

11. Oppenheim, A.N. (2001). Questionnaire Design, Interviewing and Attitude Measurement. Continuum. New York, NY:

12. Phinney, J. S. (1996). When We Talk About American Ethnic Groups, What Do We Mean? American Psychologist. 51(9): 918-27. 
13. Ramirez, R. R. and G. P. de la Cruz. (2000). The Mexican-American Population in the United States: March 2002. Current Population Reports, P20-545, U.S. Census Bureau, Washington D.C.

14. Sabogal, F., Marin, G., Otero-Sabogal R., Mari, B., and E. Perez-Stable. (1987). Hispanic Famialism and Acculturation: What Changes and What Doesn't? Hispanic Journal of Behavioral Sciences. 9: $397-412$.

15. Smith, P.C., Kendall, L.M., and C. L. Hulin. (1969). Measurement of Satisfaction in Work and Retirement. Rand McNally. Chicago, IL.

16. Sosa, L. (1998). The American Dream. Dutton. New York, NY.

17. Spector, P. E. (1985). Measurement of Human Service Staff Satisfaction: Development of the Job Fulfillment Survey. American Journal of Community Psychology 13(6): 693-713.

18. Spector, P.E. (1997). Job Fulfillment: Application, Assessment, Causes, and Consequences. Sage Publications. Thousand Oaks, CA:

19. Stevens, J. (1986). Applied Multivariate Statistics for the Social Sciences. Lawrence Erlbaum Associates, Publishers. Hillsdale, NJ

20. Triandis, H. (1994). Theoretical and Methodological Approaches to the Study of Collectivism and Individualism. In Kim. U., Triandis, H., Kagitcibasi, C., Choi, S., and G. Yoon (Eds.). Individualism and Collectivism: Theory, Methods, and Applications. Sage Publications. Thousand Oaks, CA. 41-51.

21. U.S. Census Bureau, U.S. Department of Commerce, Economics and Statistics Administration: (2000). The Hispanic population, Census 2000 Brief: May 2001.

22. Weaver, C. N. (2000). Work Attitudes of Mexican-Americans. Hispanic Journal of Behavioral Sciences. 22(3): 275-295.

23. Williams, P. A., Moyes, G. D. and B. Koch. (2004). The Effect of Age on Gender - Differentiated Perceptions of Job Attributes Among Accounting Professionals. Working Paper. 